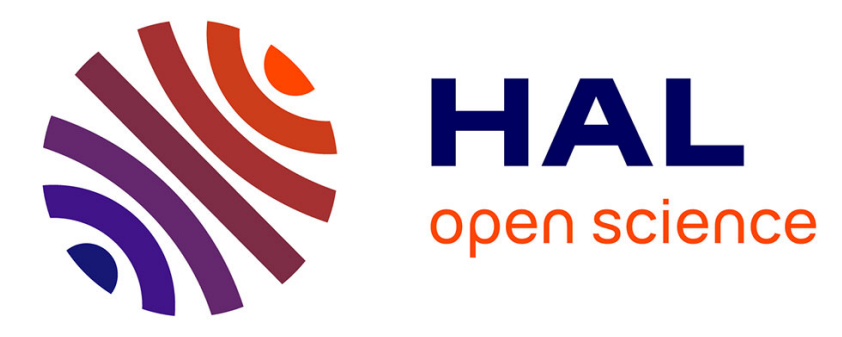

\title{
Atomic scale investigations on CdxZn1-xSe quantum dots: Correlation between the composition and emission properties
}

H. Benallali, T. Cremel, K. Hoummada, Dominique Mangelinck, R. André, S. Tatarenko, Kuntheak Kheng

\section{To cite this version:}

H. Benallali, T. Cremel, K. Hoummada, Dominique Mangelinck, R. André, et al.. Atomic scale investigations on CdxZn1-xSe quantum dots: Correlation between the composition and emission properties. Applied Physics Letters, 2014, 105 (5), pp.053103. 10.1063/1.4891635 . hal-01221881

\section{HAL Id: hal-01221881 \\ https://hal.science/hal-01221881}

Submitted on 26 May 2021

HAL is a multi-disciplinary open access archive for the deposit and dissemination of scientific research documents, whether they are published or not. The documents may come from teaching and research institutions in France or abroad, or from public or private research centers.
L'archive ouverte pluridisciplinaire HAL, est destinée au dépôt et à la diffusion de documents scientifiques de niveau recherche, publiés ou non, émanant des établissements d'enseignement et de recherche français ou étrangers, des laboratoires publics ou privés. 


\section{Atomic scale investigations on $\mathrm{Cd}_{\mathrm{x}} \mathrm{Zn}_{1-\mathrm{x}} \mathrm{Se}$ quantum dots: Correlation between the composition and emission properties}

Cite as: Appl. Phys. Lett. 105, 053103 (2014); https://doi.org/10.1063/1.4891635

Submitted: 30 April 2014 . Accepted: 13 July 2014 . Published Online: 05 August 2014

H. Benallali, T. Cremel, K. Hoummada, D. Mangelinck, R. André, S. Tatarenko, and K. Kheng

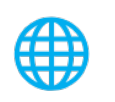

\section{ARTICLES YOU MAY BE INTERESTED IN}

Band parameters for III-V compound semiconductors and their alloys

Journal of Applied Physics 89, 5815 (2001); https://doi.org/10.1063/1.1368156

Multidimensional quantum well laser and temperature dependence of its threshold current Applied Physics Letters 40, 939 (1982); https://doi.org/10.1063/1.92959

Statistical correction of atom probe tomography data of semiconductor alloys combined with optical spectroscopy: The case of $\mathrm{Al}_{0.25 \mathrm{Ga} 0.75 \mathrm{~N}}$

Journal of Applied Physics 119, 105704 (2016); https://doi.org/10.1063/1.4943612

Challenge us.

What are your needs for periodic signal detection?

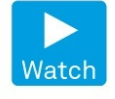

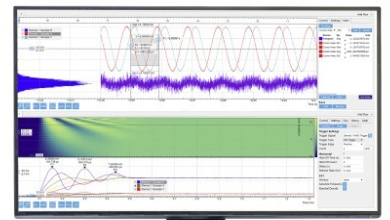

0
Zurich

- Instruments 


\title{
Atomic scale investigations on $\mathrm{Cd}_{\mathrm{x}} \mathrm{Zn}_{1-\mathrm{x}}$ Se quantum dots: Correlation between the composition and emission properties
}

\author{
H. Benallali, ${ }^{1, a)}$ T. Cremel, ${ }^{2}$ K. Hoummada, ${ }^{1}$ D. Mangelinck, ${ }^{1}$ R. André, ${ }^{2}$ S. Tatarenko, ${ }^{2}$ \\ and K. Kheng ${ }^{2}$ \\ ${ }^{1}$ Aix-Marseille Université, IM2NP-CNRS, Case 142, 13397 Marseille Cedex 20, France \\ ${ }^{2}$ University of Grenoble Alpes, F-38000 Grenoble, France; CEA, INAC, F-38054 Grenoble, France; \\ and CNRS, Inst. NEEL, F-38042 Grenoble, France
}

(Received 30 April 2014; accepted 13 July 2014; published online 5 August 2014)

\begin{abstract}
Atom probe tomography and photoluminescence spectroscopy have been used to study $\mathrm{Cd}_{\mathrm{x}} \mathrm{Zn}_{1-\mathrm{x}} \mathrm{Se}$ quantum dots embedded in a $\mathrm{ZnSe}$ layer grown on a (001) GaAs substrate. Atom probe tomography analyses show significant cadmium incorporation in the center of the dots surrounded by poor cadmium region. These measurements illustrate that the maximum cadmium concentration in the quantum dots is significantly higher than the concentration estimated by transmission electron microscopy. The composition and size of quantum dots obtained by atom probe tomography have been used to calculate the transition energies including excitonic and strain effects. (C) 2014 AIP Publishing LLC. [http://dx.doi.org/10.1063/1.4891635]
\end{abstract}

CdSe/ZnSe quantum dots (QDs) have attracted much interest due to their possible application in optoelectronics. ${ }^{1}$ In the 90s, the basic application for CdSe/ZnSe QDs was connected to short wave emitters and manufacturing of QDs laser. Recently, CdSe QDs have gained more interest as sources of single photon operating at room temperature. ${ }^{2}$ II-VI self-assembled QDs such as CdSe/ZnSe are promising system for single-photon emission in the blue-green range. ${ }^{3}$ The optical properties of QDs systems depend on many parameters such as morphology, chemical composition, and chemical environment. ${ }^{4}$ In contrast to III-V materials like InAs/GaAs, the formation of CdSe QDs differs significantly from the Stransky-Krastanov growth mode ${ }^{5}$ so that interdiffusion and/or segregation phenomena based on $\mathrm{Cd}-\mathrm{Zn}$ exchange ${ }^{6,7}$ may take place in the QD formation mechanism.

In order to obtain specific properties, comprehensive nanoscale information about the dots and their surroundings are required. However, the chemical analysis of embedded QDs is challenging. Transmission electron microscopy (TEM) can give first estimation of the degree of intermixing between CdSe and ZnSe layers. The key strength of TEM is that it can directly visualize the atomic structure of a material, and a recent approach has aimed at analyzing the $\mathrm{CdSe}$ QDs composition using the change in lattice parameters in high resolution TEM (HRTEM) images. ${ }^{8,9}$ This is an indirect method to derive information about composition. On the other hand, the strength of Atom Probe Tomography (APT) is its ability to give directly information about the $3 \mathrm{D}$ composition of all chemical elements at atomic scale. ${ }^{10}$ Thus, APT has been used recently to investigate the composition of III-V QDs, ${ }^{11}$ II-VI layers, and II-VI/III-V interface at atomic scale. $^{12}$

In this paper, we investigate the chemical composition and sizes of $\mathrm{Cd}_{\mathrm{x}} \mathrm{Zn}_{1-\mathrm{x}}$ Se QDs embedded in $\mathrm{ZnSe}$ by APT and we correlate these measurements to their emission energy in photoluminescence (PL) spectra.
The sample presented in this study is composed of a single CdSe QD plane inserted between ZnSe barriers grown by molecular beam epitaxy (MBE). First, $60 \mathrm{~nm}$ thick ZnSe buffer layer was grown at $280^{\circ} \mathrm{C}$ on a (100) GaAs substrate. Then 3 monolayers (MLs) of CdSe were deposited on the $\mathrm{ZnSe}$ layer by atomic layer epitaxy (at $280^{\circ} \mathrm{C}$ ). To induce the 2D-3D transition of the strained CdSe layer, amorphous selenium was first deposited at low temperature $\left(10^{\circ} \mathrm{C}\right)$ and then desorbed by heating up to $240^{\circ} \mathrm{C}$ where spotty $3 \mathrm{D}$ RHEED (reflection high-energy electron diffraction) patterns appear and typically indicate QD formation. ${ }^{13}$ Finally, the CdSe QD layer was capped with $40 \mathrm{~nm} \mathrm{ZnSe}$ layer (grown in two steps: $2 \mathrm{~min}$ at $240^{\circ} \mathrm{C}$ then $5 \mathrm{~min}$ at $280^{\circ} \mathrm{C}$ ). Details of the growth method can be found in Ref. 13.

Prior to APT analysis, low-temperature $(10 \mathrm{~K})$ photoluminescence and micro-photoluminescence measurements were performed on the sample. For APT analysis, a $100 \mathrm{~nm}$ thick Ni protection layer was deposited by physical vapor deposition. The samples were shaped into tips along the (001) growth direction using the lift-out technique and the annular milling method with a Ga focused ion beam. The specimen preparation was performed in a FEI Helios dualbeam-Focused ion beam (FIB) and APT measurements in a LEAP 3000X HR microscope. This microscope is equipped with a pulsed-laser source $(\lambda=532 \mathrm{~nm}$, pulse duration $\sim 10$ ps, spot size $<5 \mu \mathrm{m}$ ). The analysis conditions and specimen preparation techniques were carefully determined in order to optimize the APT analysis. In particular, reducing the laser energy and increasing the evaporation rate and/or the tip shape allow us to obtain good stoichiometry for semiconductor compounds by minimizing the molecular ions formation and by taking into account the peaks overlapping. APT measurements were carried out at $23 \mathrm{~K}$ under a pressure below $5 \times 10^{-11}$ Torr and using a picosecond laser pulse with energy of $0.004 \mathrm{~nJ}$ and $100 \mathrm{kHz}$ laser repetition. During the analysis, an evaporation rate of 0.002 ions per pulse was kept constant. The 3D reconstruction was carried out by using the shank-based algorithm ${ }^{14-16}$ in the IVAS commercial software, a field factor of 3.3 and an evaporation field of

a)hammouda.benallali@im2np.fr 
$23 \mathrm{~V} / \mathrm{nm}$ to provide flat interface and layer thicknesses close to value measured by TEM.

Figure 1 (a) shows the $90 \times 90 \times 100 \mathrm{~nm}^{3}$ volume obtained by the reconstruction of APT data, in which the layers of $\mathrm{ZnSe}$ and $\mathrm{CdSe}$ are clearly visible on the GaAs substrate. From the atom distribution in this $3 \mathrm{D}$-volume, a $15 \mathrm{~nm}$ diameter cylinder perpendicular to the $\mathrm{ZnSe} / \mathrm{CdSe}$ interface was used to extract a one dimensional (1D) mean concentration along the axe of the reconstructed volume (Fig. 1(b)). The small diameter $(15 \mathrm{~nm})$ helps to reduce the effects of curvature in the reconstruction and the misalignment of the cylinder, both of which could result in loss of accuracy for the characterization of the CdSe layer. This 1D composition profile shows that the average composition of $\mathrm{ZnSe}$ is in very good agreement with the 50:50 stoichiometry. The mean composition of $\mathrm{Cd}$ measured in $\mathrm{Cd}_{\mathrm{x}} \mathrm{Zn}_{1-\mathrm{x}} \mathrm{Se}$ layer corresponds to $\mathrm{x}=0.37$, and the layer thickness is about $3-4 \mathrm{~nm}$. The Se concentration is constant through all the II-VI layer meaning that $\mathrm{Zn}$ and $\mathrm{Cd}$ substitute each other as expected.

From the APT measurements, two dimensional (2D) mapping has also been extracted to show $\mathrm{Cd}$ atoms lateral distribution in the $\mathrm{Cd}_{\mathrm{x}} \mathrm{Zn}_{1-\mathrm{x}} \mathrm{Se}$ layer. Figure 2 shows the $2 \mathrm{D}$ maps of the $\mathrm{Cd}$ concentration obtained by integrating (a) over $3 \mathrm{~nm}$ along the z-direction (growth direction) in a $50 \times 50 \times 3 \mathrm{~nm}^{3}$ slice, (b) over $3 \mathrm{~nm}$ along the $\mathrm{x}$ direction in a $3 \times 44 \times 24 \mathrm{~nm}^{3}$ slice, and (c) over $15 \mathrm{~nm}$ along the $\mathrm{x}$ direction in a

(a)

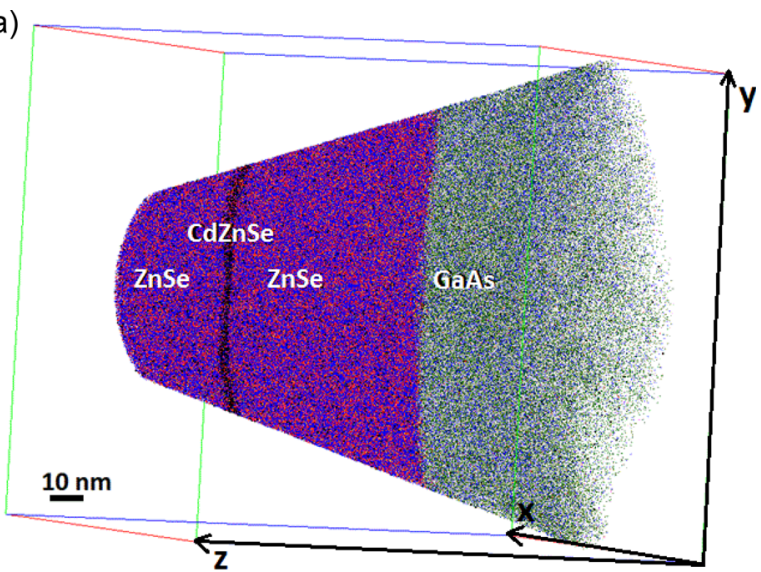

(b)

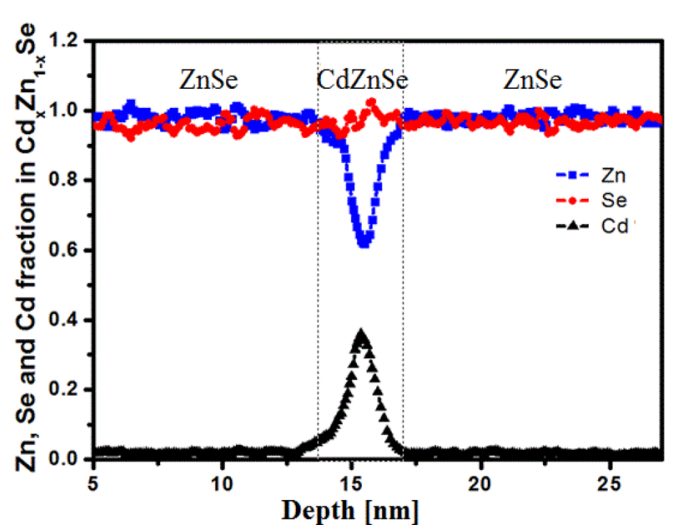

FIG. 1. (a) Reconstructed volume $90 \times 90 \times 100 \mathrm{~nm}^{3}$, showing the $\mathrm{ZnSe} /$ $\mathrm{CdSe} / \mathrm{ZnSe}$ layers on top of the GaAs substrate. The 3D atom map shows the abrupt interface between layers. (b) Concentration profile measured inside a cylinder of $15 \mathrm{~nm}$ diameter in the reconstructed volume above, along the growth direction $\mathrm{z}$; the average concentration of $\mathrm{Cd}$ is about 0.37 in the $\mathrm{Cd}_{\mathrm{x}} \mathrm{Zn}_{1-\mathrm{x}} \mathrm{Se}$ layer.
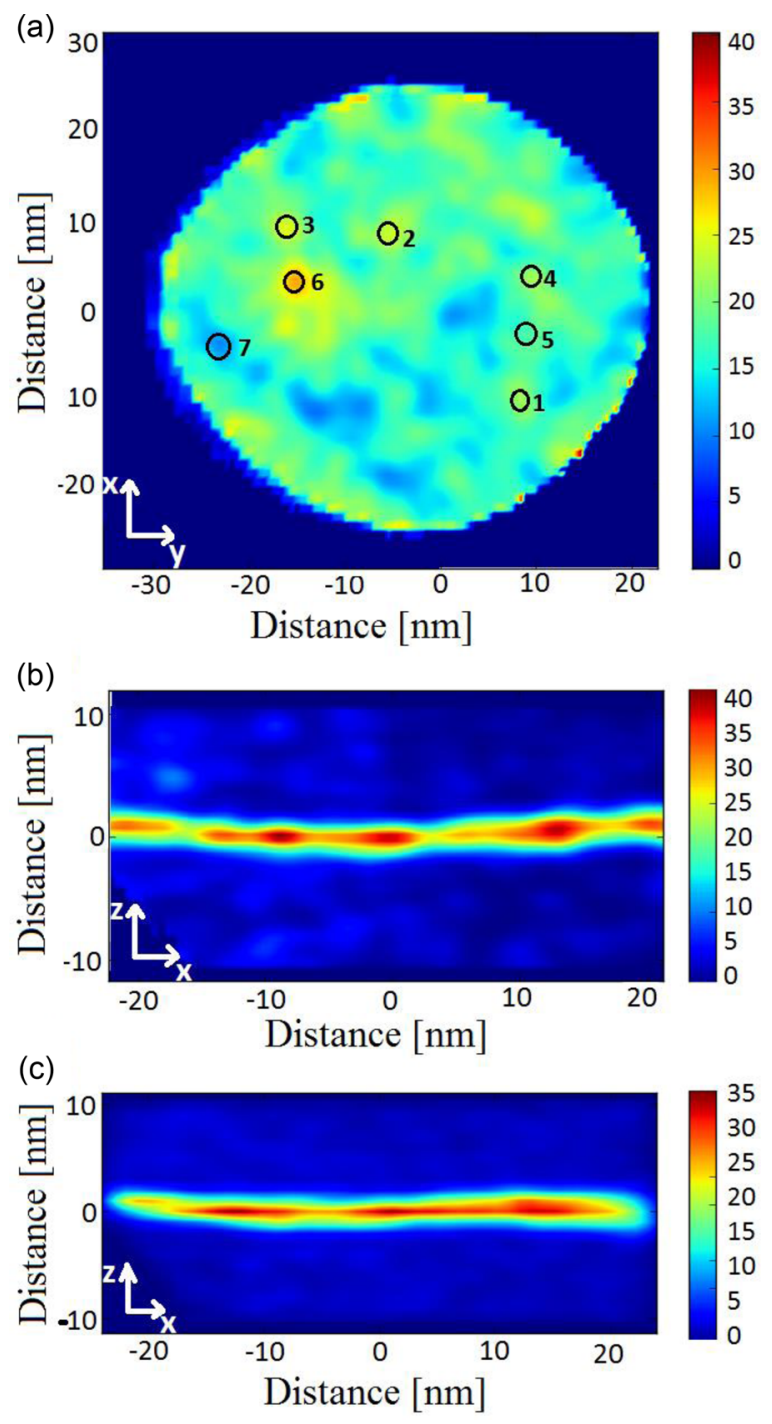

FIG. 2. (a) 2D map concentration obtained from $3 \mathrm{~nm}$ slice through the CdZnSe layer along the growth direction, (b) 2D map obtained from $3 \mathrm{~nm}$ slice through the CdZnSe layer perpendicular to growth direction. (c) $2 \mathrm{D}$ map obtained from $15 \mathrm{~nm}$ slice through the $\mathrm{CdZnSe}$ layer perpendicular to growth direction. The color range goes from blue (poor Cd concentration) to red (high Cd concentration).

$15 \times 44 \times 24 \mathrm{~nm}^{3}$ slice. These $2 \mathrm{D}$-mapping shows clearly variations of the $\mathrm{Cd}$ concentration within the $\mathrm{Cd}_{\mathrm{x}} \mathrm{Zn}_{1-x}$ Se layer: small Cd-rich regions are surrounded by $\mathrm{Cd}$-poor regions. $\mathrm{Cd}$ rich regions are attributed to $\mathrm{Cd}_{\mathrm{x}} \mathrm{Zn}_{1-\mathrm{x}} \mathrm{Se} \mathrm{QDs}$ while $\mathrm{Cd}$-poor regions correspond to the wetting layer. The lateral surface of QDs in the (x,y) plane varies between 16 and $35 \mathrm{~nm}^{2}$. Figures 2(b) and 2(c) also show an inhomogeneous Cd distribution in a slice along the (in-plane) x-direction. Figure 2(b) is a 3-nm-indepth profile (integration over $3 \mathrm{~nm}$ ) and displays the local $\mathrm{Cd}$ concentration in a $2 \mathrm{D}(\mathrm{x}, \mathrm{z})$ plane. We observe that the QD lateral size is $\sim 5-10 \mathrm{~nm}$. If we consider now the 15 -nm-in-depth profile of Fig. 2(c), we observe that the averaging of $\mathrm{Cd}$ concentration over $15 \mathrm{~nm}$ gives the impression of having larger $(\sim 20 \mathrm{~nm})$ QD lateral size. This latter 2D profile is similar to the contrast in TEM images ${ }^{17}$ and shows that TEM analysis in this case can lead to an overestimation of the lateral size.

The 2D Cd concentration maps in Fig. 2 only give an average concentration of the $\mathrm{Cd}_{\mathrm{x}} \mathrm{Zn}_{1-\mathrm{x}} \mathrm{Se}$ QDs (integration 


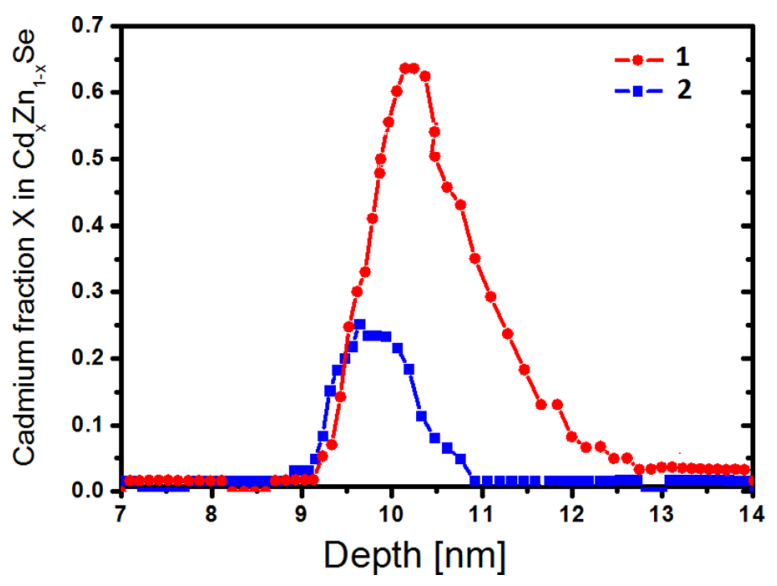

FIG. 3. 1D Cd composition profiles from two different regions in the $\mathrm{CdZnSe}$ layer using a $3 \mathrm{~nm}$ diameter cylinder. The two regions are indicated by circle nos.1 and 2 in Fig. 2(a). Profile 1 corresponds to $\mathrm{Cd}$ rich (QDs) region, and profile 2 corresponds to cadmium-poor region (wetting layer).

over the thickness of a slice). In order to obtain more accurate concentration in a $\mathrm{QD}$, we make use of $1 \mathrm{D}$ profiles across the QDs. Figure 3 shows two examples of 1D profiles generated along the z-axis using $3 \mathrm{~nm}$ diameter cylinders (cylinders are shown and labeled in Fig. 2(a)). The Cd concentration in the $\mathrm{Cd}_{x} \mathrm{Zn}_{1-x} \mathrm{Se}$ layer depends on the actual position of the intersecting cylinder. For instance, cylinder no. 6 intersects the $\mathrm{Cd}$ richest $\mathrm{QD}$ with a maximum $\mathrm{Cd}$ content of $x=0.65 \pm 0.04$. On the other hand, cylinder no. 7 intersects a thinner and $\mathrm{Cd}$-poor region with a typical $\mathrm{Cd}$ content of $x=0.26 \pm 0.04$ (profile 2 in Fig. 3) which is attributed to the wetting layer. Altogether, six QDs were identified in the volume of Fig. 1 (see Fig. 2(a)) and their characteristics are listed in Table I. We use 1D profiles to determine the Cd concentration and the height of QDs and 2D maps for their lateral dimensions. The maximum $\mathrm{Cd}$ concentration in the QDs and their height are displayed in Table I: they vary from 0.39 to 0.65 and from 2.1 to $1.4 \mathrm{~nm}$, respectively. The average concentration $(\mathrm{x})$, height $(\mathrm{h})$, width $(\mathrm{w})$, and length (l) of QDs are estimated to be $\mathrm{x}=0.50$, $\mathrm{h}=1.6 \mathrm{~nm}, \mathrm{w}=3.7 \mathrm{~nm}$, and $\mathrm{L}=6.3 \mathrm{~nm}$ with the corresponding standard deviation of $0.096,1.5 \mathrm{~nm}, 0.74 \mathrm{~nm}$, and $1.4 \mathrm{~nm}$.

We want to emphasize that the APT ability of 3D local chemical analysis provides more accurate value for size and Cd concentration within the QDs. Though TEM analysis has not been carried out in our sample, we note that the analysis of the composition dependent contrast in high resolution TEM of a similar sample (QDs formed with $3 \mathrm{ML}$ of CdSe

TABLE I. Characteristics of the QDs found in the 3D volume in Fig. 1(a): The concentration and the height were deduced from 1D profiles using $3 \mathrm{~nm}$ cylinder and the width and lengths from 2D maps. Sizes are FWHM of the concentration profiles.

\begin{tabular}{lcccc}
\hline \hline & Cd concentration (\%) & Height (nm) & Width (nm) & Length (nm) \\
\hline QD1 & 39 & 2.09 & 3 & 7 \\
QD2 & 55 & 1.4 & 5 & 7 \\
QD3 & 58 & 1.32 & 3 & 8 \\
QD4 & 40 & 1.7 & 4 & 4 \\
QD5 & 45 & 1.6 & 3 & 7 \\
QD6 & 65 & 1.4 & 4 & 5 \\
\hline \hline
\end{tabular}

but with a different growth method) ${ }^{6}$ gives estimates of QD diameter of about $5-10 \mathrm{~nm}$ and $\mathrm{Cd}$ concentration above $40 \%$. These results are consistent with our results (though we can find significantly higher $\mathrm{Cd}$ concentration) but they much less accurate since in TEM measurements the concentration is measured through the thickness of the lamella.

To summarize this part, APT measurements do not show evidence for pure CdSe regions within our QDs sample but some $\mathrm{Cd} / \mathrm{Zn}$ intermixing. This intermixing can be due to $\mathrm{Cd} / \mathrm{Zn}$ interdiffusion or segregation of $\mathrm{Cd}$ during the growth. More precisely, TEM measurements on a sample grown by the same method, but without the cap ZnSe barrier, have shown the formation of the pure CdSe islands before the encapsulation by the second $\mathrm{ZnSe}$ barrier. ${ }^{17}$ This shows that the $\mathrm{Cd} / \mathrm{Zn}$ intermixing is due segregation effect during the overgrowth of the second barrier. ${ }^{18}$ Note that similar intermixing has been also observed for InAs/GaAs QDs. ${ }^{19-21} \mathrm{By}$ revealing the 3D distribution of the constituent elements of the $\mathrm{Cd}_{\mathrm{x}} \mathrm{Zn}_{1-\mathrm{x}} \mathrm{Se}$ QDs with atomic scale measurements, we have determined composition and size of individual QDs with Cd composition ranging from 39\% to 65\% in QDs (Cdrich regions) and $26 \%$ in the so called wetting layer (Cdpoor region). These parameters strongly affect the optical proprieties since the $\mathrm{Cd}_{\mathrm{x}} \mathrm{Zn}_{1-\mathrm{x}} \mathrm{Se}$ composition gives the band gap and the QD sizes define the confinement energies and Coulomb interaction.

In this paragraph, we want now to correlate the QD characteristics measured by APT with their emission properties. The inset of Fig. 4 shows the PL spectrum of an ensemble of QDs at $10 \mathrm{~K}$, excited by a cw $488 \mathrm{~nm}$ laser with an incident power of $200 \mu \mathrm{W}$ focused with a microscope

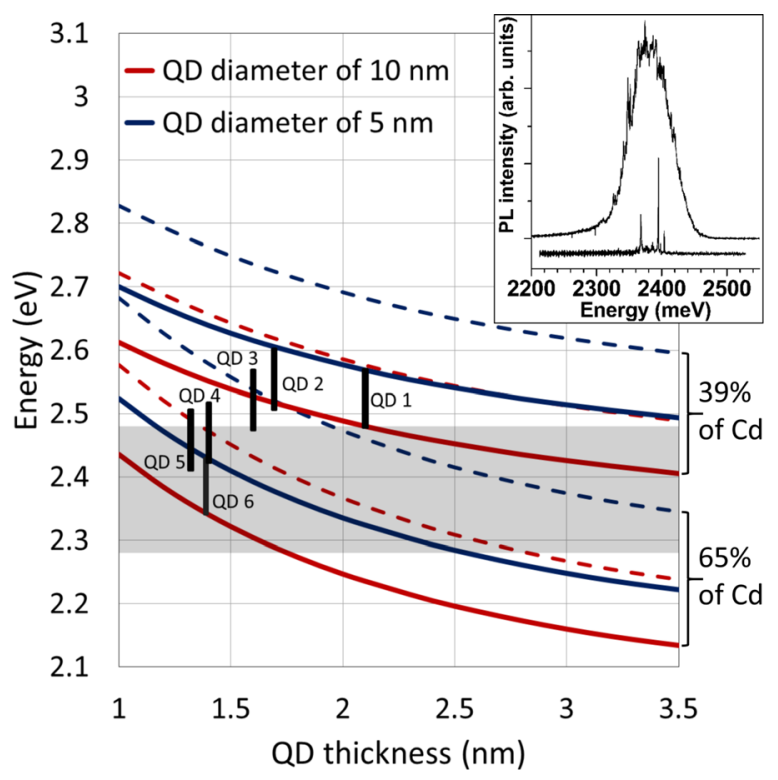

FIG. 4. PL transition energies as a function of the QD thickness. Two sets of four curves are displayed; the higher set corresponds to a $\mathrm{Cd}$ concentration of $39 \%$ and the lower set to $65 \%$ of Cd. Solid (dashed) curves are the transition energies with (without) excitonic and strain effects. Blue (red) curve is the transition energies for QD diameter of $5 \mathrm{~nm}(10 \mathrm{~nm})$. Within the $5-10 \mathrm{~nm}$ diameter, the expected transition energies are represented by vertical black rectangles for each QD whose thickness and composition has been measured by APT. The inset shows the PL spectra of an ensemble of QDs, and of a few QDs PL measured on a mesa of about $100 \mathrm{~nm}$ lateral size. The PL energy distribution is displayed by the shaded area in the figure. 
objective (N.A. $=0.4$, approximately $1 \mu \mathrm{m}$-diameter spot). The PL signal is distributed over a range of energy from 2.28 to $2.48 \mathrm{eV}$. In order to check the consistency of the APT analysis with the PL measurements, we first calculate the confinement energy of an electron and a hole assuming a lateral cylindrical shape for the QD using the effective mass model (with finite barrier and Ben Daniel-Duke boundary conditions $^{22,23}$ for the wave functions). We applied a quadratic band gap variation as a function of the $\mathrm{Cd}$ alloy composition

$$
E_{g}(x)=x E_{g_{\text {CdSe }}}+(1-x) E_{g_{\text {ZnSe }}}-b x(1-x) .
$$

We used the following experimental values: bowing parameter $b=0.35 \mathrm{eV}$, energy gaps $\mathrm{Eg}_{\mathrm{CdSe}}=1.765 \mathrm{eV}$ and $\mathrm{Eg}_{\mathrm{ZnSe}}=2.82 \mathrm{eV}$, taken from Refs. 24-26, effective masses along [100] $\mathrm{m}_{\mathrm{e}}{ }^{*}=0.12$ and $\mathrm{m}_{\mathrm{hh}}{ }^{*}=0.9$ for $\mathrm{CdSe},{ }^{27}$ $\mathrm{m}_{\mathrm{e}}{ }^{*}=0.145$ and $\mathrm{m}_{\mathrm{hh}}{ }^{*}=1.04$ for $\mathrm{ZnSe} .{ }^{28}$ A linear interpolation from the binary materials values was used to determine the alloy effective masses. The main confinement energy is given by the QD thickness (size along the growth axis z). We calculated the lateral confinement ${ }^{29}$ of the QDs for two diameters of 5 and $10 \mathrm{~nm}$ to cover the QDs lateral size distribution and we obtained values of 160 and $54 \mathrm{meV}$, respectively. In Figure 4, dashed lines display the calculated transition energies as a function of the QD thickness, taking into account the alloy concentration and the lateral confinement. This calculation does not take into account the exciton effect and gives, as expected, transition energies higher than the experimental PL energy distribution illustrated by a shaded area in Figure 4.

We used the software Nextnano ${ }^{30}$ to compute both the exciton effect and the strain effect induced by the lattice mismatch between $\mathrm{ZnSe}$ and the QD ternary alloy $\mathrm{Cd}_{\mathrm{x}} \mathrm{Zn}_{1-\mathrm{x}} \mathrm{Se}$. Strain depends on the $\mathrm{Cd}$ concentration and we computed values of -4 and $-25 \mathrm{meV}$ for the extrema $\mathrm{Cd}$ concentrations of 39\% (QD1) and 65\% (QD6), respectively. Besides, the exciton binding energy depends on the QD diameter. Thus, for QDs diameter of 5 and $10 \mathrm{~nm}$, we computed values of -87 and $-69 \mathrm{meV}$ by calculating in both cases the average exciton binding energy over the QDs thickness measured by APT. In Figure 4, solid lines correspond to transition energies taking into account strain and exciton effects. Similar calculations have been performed for the other QDs (QD2-QD 5) according to their thickness and Cd concentration. The vertical black rectangles correspond to each QD transition energy and show the energy dispersion as a function of the QD diameter from 5 to $10 \mathrm{~nm}$.

We observe that within the $5-10 \mathrm{~nm}$ lateral size confinement, the calculated transition energies of the QDs are included in the PL energy distribution, except for QD no. 2. This latter QD is composed of $40 \%$ of $\mathrm{Cd}$, a concentration close to the $26 \%$ of the wetting layer. Thus, the carriers photo-created in such a QD are rather shallowly confined and can easily escape (by tunneling through the wetting layer) to a larger QD where they recombine.

In summary, APT provides a powerful 3D characterization of $\mathrm{Cd}_{x} \mathrm{Zn}_{1-x} \mathrm{Se}$ quantum dots at the atomic scale. This study has revealed the variability of dot size and shape, the complexity of their chemistry, and a strong intermixing between the $\mathrm{Cd}$ and the $\mathrm{Zn}$ in the quantum dots. The comparison between the PL emission energy and the calculation of the transition energies including excitonic and strain effects shows that the PL measurements and the APT study are quantitatively consistent.

The authors gratefully acknowledge Eva Monroy and Joël Cibert for fruitful discussions. This work was supported by the French National Research Agency (ANR project Magwires ANR-11-BS10-013).

${ }^{1}$ T. Passow, H. Heinke, J. Falta, K. Leonardi, and D. Hommel, Appl. Phys. Lett. 77, 3544 (2000).

${ }^{2}$ O. Fedorych, C. Kruse, A. Ruban, D. Hommel, G. Bacher, and T. Kümmell, Appl. Phys. Lett. 100, 061114 (2012).

${ }^{3}$ H. Lohmeyer, C. Kruse, K. Sebald, J. Gutowski, and D. Hommel, Appl. Phys. Lett. 89, 091107 (2006).

${ }^{4}$ A. P. Alivisatos, Science 271(5121), 933 (1996).

${ }^{5}$ D. Litvinov, A. Rosenauer, D. Gerthsen, P. Kratzert, M. Rabe, and F. Henneberger, Appl. Phys. Lett. 81,640 (2002).

${ }^{6}$ T. Passow, K. Leonardi, H. Heinke, D. Hommel, D. Litvinov, A. Rosenauer, D. Gerthsen, J. Seufert, G. Bacher, and A. Forchel, J. Appl. Phys. 92, 6546 (2002).

${ }^{7}$ T. Passow, H. Heinke, T. Schmidt, J. Falta, A. Stockmann, H. Selke, P. Ryder, K. Leonardi, and D. Hommel, Phys. Rev. B 64,193311 (2001).

${ }^{8}$ N. Peranio, A. Rosenauer, D. Gerthsen, S. V. Sorokin, I. V. Sedova, and S. V. Ivanov, Phys. Rev. B 61, 16015 (2000).

${ }^{9}$ D. Litvinov, A. Rosenauer, D. Gerthsen, and N. Ledentsov, Phys. Rev. B 61, 16819 (2000).

${ }^{10}$ A. Cerezo, D. Gibuoin, S. Kim, S. J. Sijbrandij, F. M. Venker, P. J. Warren, J. Wilde, and G. D. W. Smith, J. Phys. IV France 06, C5-205 (1996).

${ }^{11}$ M. Müller, A. Cerezo, G. D. W. Smith, L. Chang, and S. S. A. Gerstl, Appl. Phys. Lett. 92, 233115 (2008).

${ }^{12}$ H. Benallali, K. Hoummada, M. Descoins, P. Rueda-Fonseca, L. Gerard, E. Bellet-Amalric, S. Tatarenko, K. Kheng, and D. Mangelinck, Scr. Mater. 69(7), 505 (2013).

${ }^{13}$ I. C. Robin, R. André, H. Mariette, S. Tatarenko, Le Si Dang, J. Bleuse, E. Bellet-Amalric, and J. M. Gérard, Nanotechnology 16, 1116 (2005).

${ }^{14}$ F. Vurpillot, B. Gault, B. P. Geiser, and D. J. Larson, Ultramicroscopy 132, 19(2013)

${ }^{15}$ E. A. Marquis, B. P. Geiser, T. J. Prosa, and D. J. Larson, J. Microsc. 241, 225 (2011).

${ }^{16}$ M. K. Miller and M. G. Hetherington, Surf. Sci. 246, 442 (1991).

${ }^{17}$ I.-C. Robin, R. André, C. Bougerol, T. Aichele, and S. Tatarenko, Appl. Phys. Lett. 88, 233103 (2006).

${ }^{18}$ T. Passow, K. Leonardi, H. Heinke, T. Schmidt, J. Falta, A. Stockmann, H. Selke, and D. Hommel, Physica E 13, 1208 (2002).

${ }^{19}$ Z. R. Wasilewski, S. Fafard, and J. P. McCaffrey, J. Cryst. Growth 202, 1131 (1999).

${ }^{20}$ N. Grandjean, J. Massies, and O. Tottereau, Phys. Rev. B 55, R10189 (1997).

${ }^{21}$ C. Priester and M. Lannoo, Appl. Surf. Sci. 123-124, 658 (1998).

${ }^{22}$ J. W. Conley, C. B. Duke, G. D. Mahan, and J. J. Tiemann, Phys. Rev. 150, 466 (1966).

${ }^{23}$ D. J. BenDaniel and C. B. Duke, Phys. Rev. 152, 683 (1966).

${ }^{24}$ A. G. Areshkin, G. S. Pecar, G. N. Polisskii, T. B. Popova, L. G. Suslina, and D. L. Fedorov, Sov. Phys. Solid State 28, 2109 (1986).

${ }^{25}$ H. C. Poon, Z. C. Feng, Y. P. Feng, and M. F. Li, J. Phys.: Condens. Matter 7, 2783 (1995).

${ }^{26}$ W. Shan, J. J. Song, H. Luo, and J. K. Furdyna, Phys. Rev. B 50, 8012 (1994).

${ }^{27}$ Y. D. Kim, M. V. Klein, S. F. Ren, Y. C. Chang, H. Luo, N. Samarth, and J. K. Furdyna, Phys. Rev. B 49, 7262 (1994).

${ }^{28}$ M. Isshiki, J. Cryst. Growth 86, 615 (1990).

${ }^{29}$ N. C. Constantinou and B. K. Ridley, J. Phys.: Condens. Matter 1, 2283 (1989).

${ }^{30}$ S. Birner, T. Zibold, T. Andlauer, T. Kubis, M. Sabathil, A. Trellakis, and P. Vogl, IEEE Trans. Electron Devices 54, 2137 (2007). 